\title{
Effect of Chlorophyllin on Biomphalaria alexandrina Snails and Schistosoma mansoni Larvae
}

\author{
Heba A. Elhadad ${ }^{1}$, Bassem A. El-Habet ${ }^{1}$, Rania M. Azab ${ }^{2}$, Hanaa M. Abu El Einin ${ }^{3}$, \\ Wael M. Lotfy ${ }^{4}$ and Hassan A. Atef ${ }^{5^{*}}$
}

${ }^{1}$ Department of Parasitology, Medical Research Institute, Alexandria University, Alexandria, Egypt

${ }^{2}$ National Institute of Laser Department, National Institute of Laser Enhanced Science (NILES), Cairo University, Giza, Egypt

${ }^{3}$ Department of Environmental Researches and Medical Malacology, Theodor Bilharz Research Institute, Imbaba, Giza, Egypt

${ }^{4}$ Department of Community Health Nursing, Faculty of Nursing, Alexandria UniversityMatrouh Branch, Marsa Matrouh, Egypt

${ }^{5}$ Department of Mycology and Mycotoxins, Animal Health Research Institute, Agriculture Research Centre, Dokki, Cairo, Egypt

*Corresponding author

\section{Keywords}

Schistosomiasis, Snail, Control, Chlorophyllin, Photosensitization

\section{Article Info}

Accepted:

28 February 2018

Available Online:

10 March 2018

\section{A B S T R A C T}

The present study was undertaken to investigate the lethal activity of chlorophyllin against different developmental stages of Biomphalaria alexandrina snails and Schistosoma mansoni aquatic larvae under laboratory conditions. In all experiments, the studied organisms were incubated in different chlorophyllin concentrations in the dark, and then exposed to sunlight to stimulate the lethal photosensitizing action of chlorophyllin. Snails lethal concentrations for six hours of sunlight exposure were as follows: $\mathrm{LC}_{90}(131.86 \mathrm{ppm}), \mathrm{LC}_{50}(82.68 \mathrm{ppm}), \mathrm{LC}_{25}$ $(56.93 \mathrm{ppm})$ and $\mathrm{LC}_{10}(33.76 \mathrm{ppm})$. The lethal action of chlorophyllin is affected by several factors including: light source, duration of sunlight exposure, the developmental stage of the snails and the presence of infection. On the cellular level, histological sections revealed marked destruction of certain tissues with loss of their landmarks. Chlorophyllin also had a profound lethal effect on the larval stages of Schistosoma mansoni. So, chlorophyllin is a promising substance of plant origin that could be used in snail control programs. 


\section{Introduction}

Schistosomiasis is one of the most important snail borne parasitic infections with a significant public health impact (King, 2009). Hence, the introduction of novel drugs for disease treatment and improvement in water supply and sanitation facilities in endemic areas, resulted in that the snail control is perhaps employed less often as a means of combating the disease. However, it remains an important and effective measure, especially where transmission occurs to a significant extent to children throughout playing in contaminated water with parasite. This type of water contact is not likely to be changed through health education and the provision of safe water supplies (Useh, 2012). Several studies evaluated the Snail control by using chemical and plant molluscicides, biological predators and ecological methods and indicated that the chemical control was one of the most important tool for the control of the pulmonate snail intermediate hosts (McCullough, 1992).

On the other hand, other studies reported that the Photosensitization is the administration of a photoactive compound that selectively accumulates in the target cells which will be killed following irradiation with visible light (Luksiene, 2005; Redmond, 2008). It was effective in inactivation of different microorganisms such as bacteria, yeasts, viruses and parasites. Photosensitization can open new and interesting avenues for the development of novel, effective and ecologically friendly photopesticides and antimicrobial agents.

Since several decades, the development of photosensitizers came along through many stages and many studies specifically designed to investigate the insecticidal activity of various dyes in the presence of visible light. Where, Graham (1963) was one of the first scientists who paid attention to the possibility of using "photosensitizing agents" as insecticides.

Recently, many studies were done using different photosensitizers to investigate photosensitic effect on parasites, snails and mosquito larvae all in aquatic ecosystems. (Salama et al., 2002; El-Tayeb, 2003; ElTarky, 2005; Wohllebe, 2010 and Ragheb, 2013)

As human Schistosomiasis mansoni is still one of the major health problems in Egypt (Barakat, 2013 and Lotfy, 2009). Using chlorophyllin in as a photosensitizer for control of the intermediate host, Biomphalaria snails by (Mahmoud et al., 2013; Ragheb, 2013; Ragheb et al., 2013). However, the used different preparations of chlorophyllingave different inaccurate lethal concentration

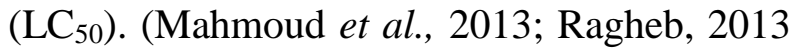
and Ragheb et al., 2013). Hence, it was important to use a standard chlorophyllin preparation and carry out the experiments under standard conditions to obtain the accurate $\mathrm{LC}_{50}$ values.

Therefore, the present study was undertaken to investigate the lethal effect of chlorophyllin on Biomphalaria alexandrina snails and freeliving stages of $S$. mansoni under standard conditions which were studied for the first time.

\section{Materials and Methods}

\section{Chlorophyllin sodium copper salt}

It was purchased from Sigma Aldrich (Commercial code: c 6003). A stock solution $(1 \mathrm{gm} / \mathrm{L})$ was prepared in distilled water and was kept in the dark. The required dilutions were prepared by using an appropriate volume of the stock solution to be completed to 100 $\mathrm{ml}$ with dechlorinated water. 


\section{Biomphalaria alexandrina snails}

Biomphalaria alexandrina snails were obtained from Theodor Bilharz Research Institute (TBRI), Imbaba, Giza, Egypt. They were maintained in dechlorinated water at $\left(24 \pm 1^{\circ} \mathrm{C}\right)$ and were fed oven dried lettuce leaves daily. Fish food TetraMin ${ }^{\circledR}$ and blue green algae, mainly Nostoc muscorm, were also used as an additional food source for newly hatched and juvenile snails.

\section{Schistosoma mansoni miracidia and cercariae}

Schistosoma mansoni eggs were obtained from Schistosomiasis Biological Supply Center TBRI, Imbaba, Giza, Egypt. Miracidia were hatched in a small amount of dechlorinated water at $25 \pm 1^{\circ} \mathrm{C}$ and used directly. While, cercariae were obtained from experimentally infected Biomphalaria alexandrina snails by light-stimulated shedding in a small amount of dechlorinated water and were used directly.

\section{Experimental Design (Mahmoud et al., 2013)}

Chlorophyllin, as a photosensitizing agent, necessitates being darkly incubated with the examined organisms for a period of time to allow its accumulation within the organisms' tissues followed by sunlight irradiation for activation of its lethal potential. Accordingly, in the different experiments, $5 \mathrm{~B}$. alexandrina snails $(6-8 \mathrm{~mm})$ were incubated in chlorophyllin in darkness overnight. After that, snails were exposed to sunlight for different periods then transferred to dechlorinated water to recover in darkness for 24 hours. Later on, viability was assessed: snails showing no vital signs (movements or reflexes after tipping with a needle) were considered dead. In each experiment, 3 replicates were used.

\section{Light and dark controls}

Light and dark controls were allowed to run along with the test samples. In light control, the tested organisms (snails, miracidia and cercariae) were exposed to the same experimental conditions without being incubated with chlorophyllin. While the dark control involved incubation of the tested organisms with the highest concentration of chlorophyllin applied in the experiment in the dark under the same experimental conditions without sunlight exposure.

Standardization of chlorophyllin sodium copper salt application method

\section{Effect of light source on molluscicidal properties}

Two series of $B$. alexandrina snails were incubated in $100 \mathrm{ml}$ of 150,100 and $50 \mathrm{mg} / \mathrm{l}$ of chlorophyllin solution overnight. The $1^{\text {st }}$ series was exposed to artificial light (desk lamp, $100 \mathrm{w} / 15 \mathrm{~cm}$ height) and the $2^{\text {nd }}$ series was exposed to sunlight for 6 hours. Thereafter, the snails were thoroughly washed and transferred to clean dechlorinated water to recover in the dark and their viability was assessed the next day.

\section{Effect of snail recovery from chlorophyllin before exposure to sunlight}

Two series of $B$. alexandrina snails were incubated in $100 \mathrm{ml}$ of the concentrations 150 , 100 and $50 \mathrm{mg} / \mathrm{l}$ of chlorophyllin solution overnight, and then were exposed to sunlight for 6 hours. The $1^{\text {st }}$ series was recovered from chlorophyllin into dechlorinated water before sunlight exposure. The $2^{\text {nd }}$ series was exposed without recovery from chlorophyllin. Thereafter, they were thoroughly washed and transferred to clean dechlorinated water to recover in the dark. Viability was then assessed. 
Determination of the lethal concentrations of chlorophyllin sodium copper salt to snails

Two groups of $10 \mathrm{~B}$. alexandrina snails were added to $200 \mathrm{ml}$ of the concentrations 250 , $200,150,125,100,50,25$ and $10 \mathrm{mg} / \mathrm{l}$ of chlorophyllin.

They were incubated in the dark overnight, and then were transferred to clean dechlorinated water. One group was exposed to sunlight for 6 hours and the second was exposed for 9 hours.

Thereafter, their viability was assessed and lethal concentrations were calculated using IBM SPSS statistics program with probit analysis (Finney, 1970).

Evaluation the factors affecting the molluscicidal potency of chlorophyllin lethal concentrations (calculated for six hours of sunlight exposure)

\section{Effect of duration of exposure to sunlight}

Three series of $\mathrm{LC}_{10}, \mathrm{LC}_{25}, \mathrm{LC}_{50}$ and $\mathrm{LC}_{90}$ of chlorophyllin were prepared. Snails were incubated in each concentration overnight, transferred to clean dechlorinated water and exposed to sunlight. The $1^{\text {st }}$ series was exposed to sunlight for 2 hours, the $2^{\text {nd }}$ series for 4 hours and the $3^{\text {rd }}$ series for 6 hours. Viability was then assessed.

Effect of chlorophyllin on different developmental stages of snails (Gawish $e t$ al., 2009)

$\mathrm{LC}_{25}, \mathrm{LC}_{50}$ and $\mathrm{LC}_{90}$ of chlorophyllin were prepared. Subsequently, egg masses, juvenile snails $(2-4 \mathrm{~mm})$, adult snails $(6-8 \mathrm{~mm})$ and $(>8$ $\mathrm{mm})$ were incubated overnight. They were exposed to sunlight, allowed to recover and their viability was assessed.

\section{Effect of chlorophyllin on infected snails}

$\mathrm{LC}_{25}, \mathrm{LC}_{50}$ and $\mathrm{LC}_{90}$ of chlorophyllin were prepared. Infected snails were incubated overnight and exposed to sunlight for six hours. Thereafter, snail mortality was assessed.

Histopathological effects of chlorophyllin on $B$. alexandrina snails

Snails were incubated in $\mathrm{LC}_{50}$ of chlorophyllin and exposed to sunlight for six hours. Thereafter, exposed snails together with light control snails were fixed using Bouin's solution, embedded in paraffin wax, sectioned $(5-8 \mu \mathrm{m})$ and stained by $\mathrm{H}$ and $\mathrm{E}$.

Effect of chlorophyllin on $S$. mansoni aquatic larvae

Ten millilitres of dechlorinated water containing approximately 500 freshly hatched miracidia or 100 cercariae were mixed with 10 $\mathrm{ml}$ of $\mathrm{LC}_{25}(57 \mathrm{mg} / \mathrm{l})$ to obtain a concentration of $28 \mathrm{mg} / \mathrm{l}$ according to the method of Mostafa and Gawish in 2009 with some modifications. (Mostafa and Gawish, 2009) Then, aliquots from the mixture, each containing about 30 miracidia, were incubated for different periods (30, 60, 90 minutes). They were then exposed to sunlight. Thereafter, microscopical assessment of larval viability was done alongside with the light and dark control groups. Cessation of movement for more than one minute was considered a sign of larval death. Finally, the dead organisms were counted and recorded.

\section{Statistical analyses}

Statistical analyses were run on IBM compatible PC using SPSS for windows statistical package (SPSS, 2006). Lethal concentrations were calculated using probit analysis. The mortality rates of experimental 
groups were compared using Pearson's chisquared test and if conditions of calculation were not possible, Fisher's exact or Monte Carlo exact tests were used. The value of $p$ below 0.05 was considered significant.

\section{Results and Discussion}

The molluscicidal activity of chlorophyllin against $B$. alexandrina snails and $S$. mansoni larvae using different concentrations was investigated under several experimental laboratory conditions.

The current results of the effect of light source on chlorophyllin application revealed that no mortality was noticed in the group exposed to artificial light with chlorophyllin. While, the exposed group to sunlight showed increased mortality rate with increase in chlorophyllin concentration (Table 1).

Whereas, no mortality was noticed in the dark control group denoting efficiency of chlorophyllin only after sunlight exposure.

Regarding the effect of recovering snails into dechlorinated water before sunlight exposure, it was observed that snails not recovered showed consistently higher mortality than those recovered, however the difference was not statistically significant (Table 2).

On the other hand, the use of chlorophyllin concentrations varying between $10-250 \mathrm{mg} / \mathrm{l}$ under conditions of 6 or 9 hours of sunlight exposure revealed that the exposure 9 hours to sunlight had resulted in higher snails' mortality even with very low chlorophyllin concentration (Table 3). However, the values of lethal concentrations were calculated for 6 hours of sunlight exposure after overnight incubation in order to mimic average duration of daylight in different seasons ( $\mathrm{LC}_{90}(131.86$ $\mathrm{mg} / \mathrm{l}), \mathrm{LC}_{50}(82.68 \mathrm{mg} / \mathrm{l}), \mathrm{LC}_{25}(56.93 \mathrm{mg} / \mathrm{l})$ and $\mathrm{LC}_{10}(33.76 \mathrm{mg} / \mathrm{l})$.
Currently, there were effects of some variables on chlorophyllin molluscicidal potency as the duration of sunlight exposure -after incubation with different lethal concentrations- caused profound effect on snail's mortality. In addition, it was observed that the exposure for 2 hours of sunlight resulted in no mortality. While, the exposure for 4hours and 6 hours resulted in significant snail mortality which was proportionally related to the increase in both the lethal concentration and the duration of sunlight exposure (Table 4).

In the present study, the effect of chlorophyllin on different developmental stages of snails was evaluated. The results revealed that the mortality rates were higher among adult snails size $(6-8 \mathrm{~mm})$. While, in Juvenile snails and adult snails more than $8 \mathrm{~mm}$ as well as egg masses showed lower sensitivity to the effect of chlorophyllin. Whereas, the difference in mortality rate was not statistically significant between the different groups except at $\mathrm{LC}_{90}$ (Table 5).

Significantly, the effect of chlorophyllin was greatly enhanced against infected snails compared to uninfected snails especially in the low lethal concentrations ( $\mathrm{LC}_{25}$ and $\left.\mathrm{LC}_{50}\right)$ (Table 6).

In our study, the influence of chlorophyllin treatment on $B$. alexandrina snail tissues was investigated by histological sections of head foot region, digestive and hermaphrodite glands (Figure 1). Sections of exposed snails to chlorophyllin treatment were friable with marked necrosis and vacuolar degeneration. The head foot region showed the appearance of a large central space that led to the collapse of the foot region as a result of marked cellular destruction with appearance of many vacuoles due to necrosis of unicellular glands and muscle fibres (Figure 1-B). While, there was evident complete destruction of salivary glands. 
Table.1 The incidence of mortality rate of snails exposed to artificial light or sunlight after dark chlorophyllin exposure

\begin{tabular}{|l|l|}
\hline $\begin{array}{l}\text { Chlorophyllin } \\
\text { concentration(mg/l) }\end{array}$ \\
\hline $\mathbf{5 0}$ \\
\hline $\mathbf{1 0 0}$ \\
\hline $\mathbf{1 5 0}$ \\
\hline
\end{tabular}

\begin{tabular}{|c|}
\hline $\begin{array}{c}\text { Mrtificial light } \\
(\mathbf{n}=15)\end{array}$ \\
0.0 \\
0.0 \\
0.0 \\
\hline
\end{tabular}

\begin{tabular}{|c|}
\hline $\begin{array}{c}\text { Sunlight } \\
(\mathbf{n}=\mathbf{1 5})\end{array}$ \\
26.7 \\
\hline 46.7 \\
\hline 86.7 \\
\hline
\end{tabular}

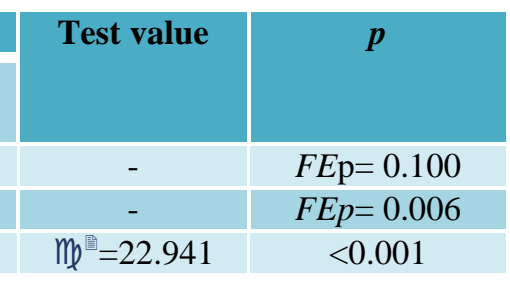

Both light and dark controls showed zero mortality rate

Table.2 The incidence of mortality rate of snails recovered from chlorophyllin before sunlight exposure compared to non-recovered snails

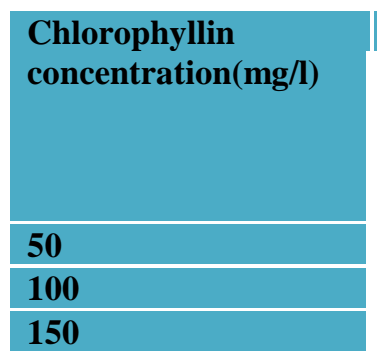

\begin{tabular}{|c|c|}
\hline \multicolumn{2}{|c|}{ Mortality rate (\%) } \\
\hline $\begin{array}{c}\text { Recovered before } \\
\text { sunlight exposure } \\
(\mathbf{n = 1 5})\end{array}$ & $\begin{array}{c}\text { Not recovered } \\
\text { before sunlight } \\
\text { exposure } \\
(\mathbf{n = 1 5})\end{array}$ \\
\hline 26.7 & 46.7 \\
\hline 46.7 & 60.0 \\
\hline 86.7 & 100.0 \\
\hline
\end{tabular}

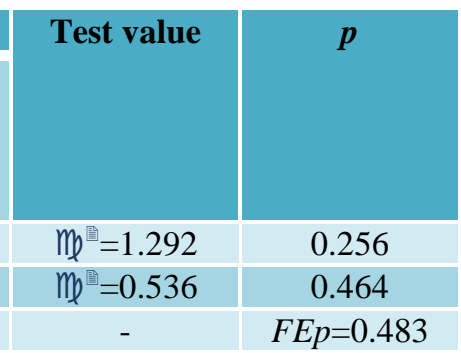

The light and dark control snail groups showed no mortality.

Table.3 The incidence of mortality rate of snails incubated in ascending concentrations of chlorophyllin followed by sunlight exposure for six or nine hours

\begin{tabular}{|l|}
\hline $\begin{array}{l}\text { Chlorophyllin concentration } \\
(\mathrm{mg} / \mathrm{l})\end{array}$ \\
\hline 10 \\
\hline 25 \\
\hline 50 \\
\hline 100 \\
\hline 125 \\
\hline 150 \\
\hline 200 \\
\hline 250 \\
\hline
\end{tabular}

\begin{tabular}{|c|c|}
\hline Mortality rate (\%) according to sunlight exposure period \\
\hline Six hours $(\mathbf{n = 1 0})$ & Nine hours $(\mathbf{n = 1 0})$ \\
\hline 0.0 & 80.0 \\
\hline 0.0 & 80.0 \\
\hline 40.0 & 100.0 \\
\hline 60.0 & 100.0 \\
\hline 80.0 & 100.0 \\
\hline 100.0 & 100.0 \\
\hline 100.0 & 100.0 \\
\hline 100.0 & 100.0 \\
\hline
\end{tabular}

Light and dark control groups showed no mortality

Table.4 The incidence of the mortality rate of snails incubated with different lethal concentrations of chlorophyllin followed by sunlight exposure for two, four and six hours

\begin{tabular}{|c|c|c|c|c|c|}
\hline \multirow[t]{2}{*}{ Lethal concentration } & \multicolumn{3}{|c|}{ Mortality rate of snails (\%) } & \multirow[t]{2}{*}{ Test value } & \multirow[t]{2}{*}{$p$} \\
\hline & $\begin{array}{l}\text { Two hours } \\
(\mathbf{n}=15)\end{array}$ & $\begin{array}{l}\text { Four hours } \\
(\mathrm{n}=15)\end{array}$ & $\begin{array}{l}\text { Six hours } \\
(\mathrm{n}=15)\end{array}$ & & \\
\hline $\mathrm{LC}_{10}$ & 0.0 & 0.0 & 0.0 & - & - \\
\hline $\mathrm{LC}_{25}$ & 0.0 & 6.6 & 20.0 & - & $M C p=0.306$ \\
\hline $\mathrm{LC}_{50}$ & 0.0 & 20.0 & 46.6 & - & $M C p=0.009$ \\
\hline $\mathrm{LC}_{90}$ & 0.0 & 40.0 & 86.6 & $m e=23.138$ & $<0.001$ \\
\hline
\end{tabular}

The light and dark control snail groups showed zero mortality rate 
Table.5 The incidence of mortality rate of snail developmental stages incubated with chlorophyllin followed by sunlight exposure for six hours

\begin{tabular}{|c|c|c|c|c|c|c|}
\hline \multirow{2}{*}{$\begin{array}{l}\text { Lethal } \\
\text { concentration }\end{array}$} & \multicolumn{4}{|c|}{ Mortality rate (\%) } & \multirow{2}{*}{$\begin{array}{c}\text { Test } \\
\text { value }\end{array}$} & \multirow[t]{2}{*}{$p$} \\
\hline & $\begin{array}{c}\text { Snail } \\
\text { eggs } \\
(n=40)\end{array}$ & $\begin{array}{c}\text { Juvenile } \\
\text { snails } \\
(2-4 \text { mm }) \\
(n=15)\end{array}$ & $\begin{array}{l}\text { Adult snails } \\
(6-8 \mathrm{~mm}) \\
(\mathrm{n}=15)\end{array}$ & $\begin{array}{l}\text { Adult snails } \\
\qquad \begin{array}{c}(>8 \mathrm{~mm}) \\
(\mathrm{n}=15)\end{array}\end{array}$ & & \\
\hline $\mathrm{LC}_{25}$ & 10.0 & 0.0 & 20.0 & 6.6 & - & $\begin{array}{c}M C \mathrm{p}=0.38 \\
7\end{array}$ \\
\hline $\mathrm{LC}_{50}$ & 30.0 & 20.0 & 46.6 & 13.3 & - & $\begin{array}{c}M C p= \\
0.222\end{array}$ \\
\hline $\mathrm{LC}_{90}$ & 52.5 & 26.7 & 86.6 & 26.7 & $\begin{array}{c}m l^{-14.6} \\
90\end{array}$ & 0.002 \\
\hline
\end{tabular}

The light and dark control for different developmental groups showed zero mortality rate

Table.6 The incidence of mortality rate of uninfected snails compared to infected snails exposed to the same experimental conditions

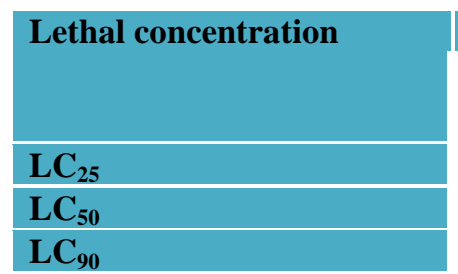

\begin{tabular}{|c|c|}
\hline \multicolumn{2}{|c|}{ Mortality rate (\%) } \\
\hline $\begin{array}{c}\text { Uninfected snails } \\
(\mathbf{n = 1 5})\end{array}$ & $\begin{array}{c}\text { Infected snails } \\
(\mathbf{n = 1 5})\end{array}$ \\
\hline 20 & 73.3 \\
\hline 46.7 & 93.3 \\
\hline 86.7 & 100 \\
\hline
\end{tabular}

\begin{tabular}{|c|c|}
\hline Test value & $\boldsymbol{p}$ \\
& \\
\hline$m=8.571$ & 0.003 \\
\hline- & $F E p=0.014$ \\
\hline- & $F E p=0.100$ \\
\hline
\end{tabular}

The light and dark control groups of the infected snails showed zero mortality rate

Table.7 The incidence of mortality rate of chlorophyllin $(28 \mathrm{mg} / \mathrm{l})$ exposed miracidia at different incubation and exposure times

\begin{tabular}{|c|c|c|c|c|c|}
\hline \multirow[t]{2}{*}{$\begin{array}{l}\text { Light exposure } \\
\text { time }\end{array}$} & \multicolumn{3}{|c|}{$\begin{array}{l}\text { Mortality rate according to incubation time in chlorophyllin } \\
\qquad(\%)\end{array}$} & \multirow[t]{2}{*}{$\begin{array}{l}\text { Test } \\
\text { value }\end{array}$} & \multirow[t]{2}{*}{$p$} \\
\hline & $\begin{array}{l}30 \text { minutes } \\
(\mathbf{n}=30)\end{array}$ & $\begin{array}{l}60 \text { minutes } \\
(\mathrm{n}=\mathbf{3 0})\end{array}$ & $\begin{array}{l}90 \text { minutes } \\
(\mathbf{n}=30)\end{array}$ & & \\
\hline 15 minutes & \begin{tabular}{l|l} 
& 10.0 \\
\end{tabular} & \begin{tabular}{l|l} 
& 30.0 \\
\end{tabular} & \begin{tabular}{l|l|} 
& 50.0 \\
\end{tabular} & 11.429 & 0.003 \\
\hline 30 minutes & 46.7 & 70.0 & 100.0 & 21.378 & $<0.001$ \\
\hline 45 minutes & 83.3 & 100.0 & 100.0 & 7.978 & 0.009 \\
\hline 60 minutes & 100.0 & 100.0 & 100.0 & - & - \\
\hline
\end{tabular}

The light and dark control groups of miracidia showed no mortality

Table.8 The incidence of mortality rate of chlorophyllin $(28 \mathrm{mg} / \mathrm{l})$ exposed cercariae at different incubation and exposure times

\begin{tabular}{|l|c|c|c|c|c|}
\hline \multirow{2}{*}{$\begin{array}{l}\text { Light exposure } \\
\text { time }\end{array}$} & \multicolumn{2}{|c|}{$\begin{array}{c}\text { Mortality rate according to dark incubation time in } \\
\text { chlorophyllin }(\mathbf{\%})\end{array}$} & $\begin{array}{c}\text { Test } \\
\text { value }\end{array}$ & $p$ \\
\hline & $\begin{array}{c}\mathbf{3 0} \text { minutes } \\
(\mathbf{n = 1 0})\end{array}$ & $\begin{array}{c}\mathbf{6 0} \text { minutes } \\
(\mathbf{n = 1 0})\end{array}$ & $\begin{array}{c}\mathbf{9 0} \text { minutes } \\
(\mathbf{n = 1 0})\end{array}$ & & \\
\hline $\mathbf{1 5}$ minutes & 20.0 & 60.0 & 100.0 & - & $M C p=0.011$ \\
\hline $\mathbf{3 0}$ minutes & 70.0 & 100.0 & 100.0 & - & $M C p=0.086$ \\
\hline $\mathbf{4 5}$ minutes & 100.0 & 100.0 & 100.0 & - & - \\
\hline
\end{tabular}

The light and dark control groups of cercariae showed no mortality. 
Fig.1 Photomicrographs of histological sections of the head foot region (A and B: original magnification 40X), digestive gland ( $\mathrm{C}$ and $\mathrm{D}$ : original magnification 100X), and hermaphrodite gland (E and F: original magnification 100X) of control snails (A, C and E) and treated snails with $\mathrm{LC}_{50}$ of chlorophyllin (B, D and F)

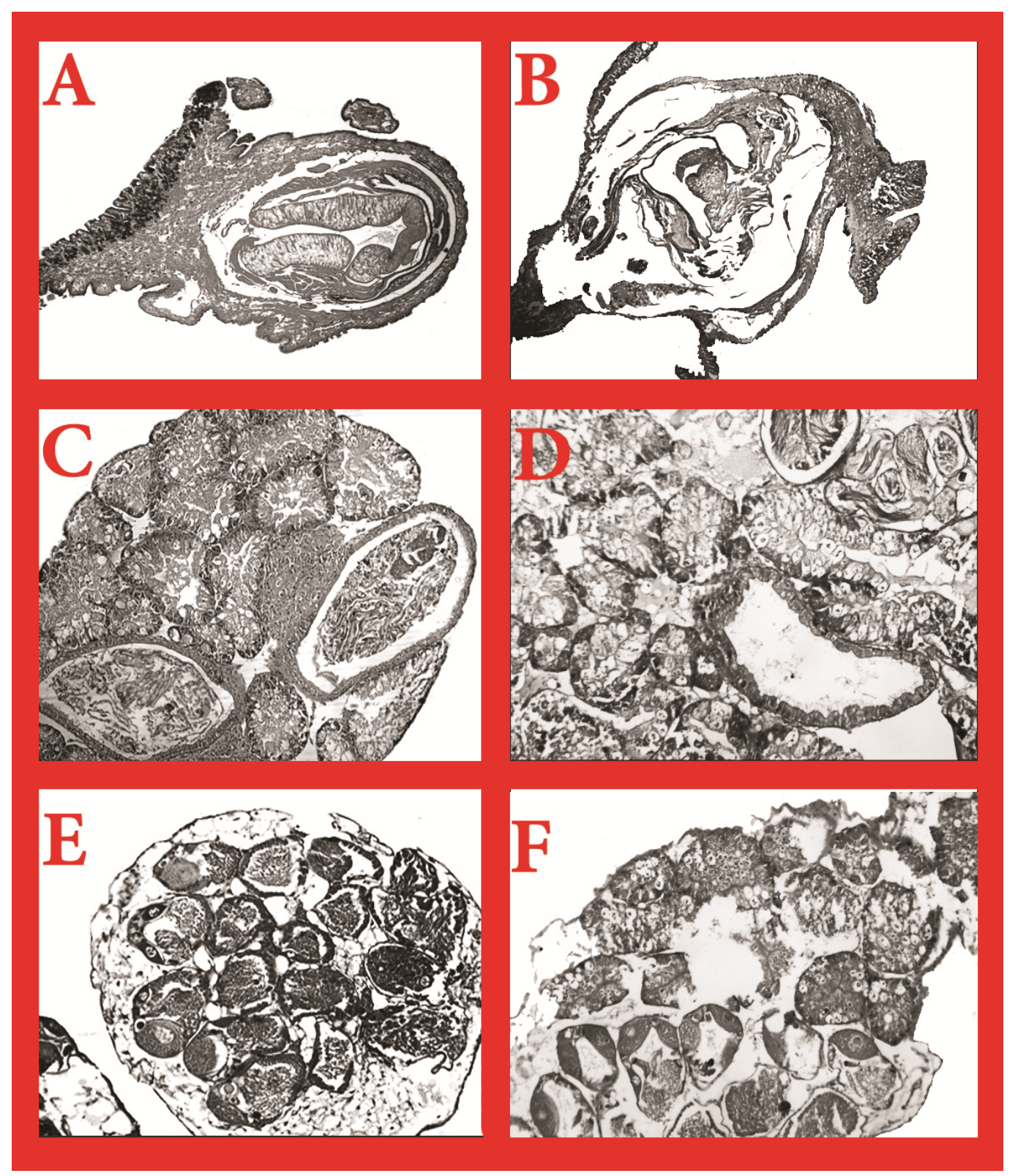

As observed in (Figure 1-D), the digestive gland showed loss of tunica propria with shrinkage of the supporting connective tissue. While, the tubular epithelial cells lost their regular shape with rupture of tips of some cells. Whereas, the glandular cells showed marked vacuolar degeneration. On the other hand, the hermaphrodite gland of the treated snails showed marked destruction of the acini (Figure 1-F), necrosis was mainly evident in the early developmental stages of gametogenesis. There was atrophy and reduction in the number of sperms. Some acini showed complete hyaline degeneration. 
Similarly, in case of Schistosoma larval stages, chlorophyllin treatment showed miracidicidal (Table 7) and cercaricidal (Table 8) effects, which were mainly governed by the dynamics of both incubation time in darkness and exposure time to sunlight. Brief incubation of larvae with chlorophyllin up to 90 minutes with $\mathrm{LC}_{25}$ resulted in $100 \%$ death of both miracidia and cercariae after 60 and 45 minutes of sunlight exposure.

The Schistosomiasis is a worldwide disease of poverty that leads to chronic health hazards (Bhattacharyya et al., 2014), during the past decades, numerous efforts have been made to control schistosomiasis throughout the world (Costa et al., 2014).

One of the popular methods to control the infection is to de-link the life cycle by killing the snail intermediate hosts (Jaiswal and Singh, 2008). Synthetic molluscicides have been widely used for the effective control of snails, but because of serious environmental hazards more researches are now being focused on molluscicides of plant origin (Srivastava and Singh, 2005; Kumar and Singh, 2006 and Jaiswal et al., 2008).

Various studies indicated that several factors may affect the lethal concentration and actions of chlorophyllin. Regarding the effect of different light sources, it was found that artificial light resulted in no mortality, while exposure to sunlight resulted in significant snail mortality. Under sunlight exposure, snail mortality was directly proportional to the increase in chlorophyllin concentration during the dark incubation phase. Similar findings were reported in earlier study on Chaoborus crystallinus which revealed that a minimum of $36 \mathrm{~W} / \mathrm{m}^{2}$ of visible daylight was needed to induce photodynamic destruction of the larvae using chlorophyllin (Erzinger et al., 2011). While, other study evaluated the effect of light source with other photosensitizers like carbamide perhydrate and it was reported that photosensitizing effect was only associated with sunlight exposure (Gawish et al., 2009).

Concerning the effect of recovery of $B$. alexandrina snails from chlorophyllin before sunlight exposure, it was noted that snails not significantly recovered showed a relatively higher mortality. This observation might be attributed to elevation of temperature of chlorophyllin solution, which may add another factor (effect of heat) during sunlight exposure. So, the recovery of snails from chlorophyllin was recommended to assess only the effect of absorbed chlorophyllin during incubation period.

In the current study, evaluation the molluscicidal properties of chlorophyllin revealed that the snail mortality rate was governed by the accumulation of chlorophyllin within the snails' tissues during dark incubation period together with the duration of sunlight exposure. In addition, the $\mathrm{LC}_{50}$ of chlorophyllin sodium copper salt for $B$. alexandrina snails, after six hours of sunlight exposure was $(82.68 \mathrm{mg} / \mathrm{l})$ and the lethal concentrations vary with different organisms. Several authors as (Wohllebe et al., 2009) noted that $\mathrm{LC}_{50}$ value for Culex sp. larvae was about $6.88 \mathrm{mg} / \mathrm{L}$. While, (Erzinger et al., 2011) showed that for Chaoborus sp. larvae $\mathrm{LC}_{50}$ was approximately $24.18 \mathrm{mg} / \mathrm{L}$. Also, Wohllebe et al., (2012) found that Ichthyophthiriu smulftifiliis was killed using $\mathrm{LC}_{50}$ of about $0.67 \mathrm{mg} / \mathrm{L}$. A higher $\mathrm{LC}_{50}$ was reported by (Mahmoud et al., 2013) who, noted that $\mathrm{LC}_{50}$ was about $30 \mathrm{mg} / \mathrm{L}$ for the snails Lymnaeastagnalis, Biomphalaria spp. And Physamarmorata. .

Regarding the effect of light dose on snail mortality, it was greatly affected and directly proportional to the duration of sunlight exposure. This may be attributed to the 
minimum time required for the initiation and the promotion of the photodynamic action of the photosensitizer. Where, chlorophyllin needed a minimum of four hours of sunlight exposure to exert its photodynamic action. These results came in accord with a previous study of (Mahmoud et al., 2013), who showed that the increased duration of sunlight exposure after chlorophyllin dark incubation was associated with higher mortality among Biomphalaria spp. snails.

In the present study, the effect of lethal concentrations of chlorophyllin on different snail developmental stages was observed that the molluscicidal effect of chlorophyllin varied with the size or age of the snails. Where, chlorophyllin had a limited lethal effect on immature snails, on adult snails more than $8 \mathrm{~mm}$ and on egg masses. This limited effect on adult snails $(>8 \mathrm{~mm})$ may be attributed to the thick shell of snails which may interfere with light penetration into the snail's tissues needed to stimulate the absorbed chlorophyllin to produce its photosensitization effect. On the other hand, the limited effect on immature snails may be attributed to the great ability of juvenile snail's tissue to regenerate. These finding were in contrary with the findings of Mahmoud et al., (2013) who reported that chlorophyllin had resulted in $100 \%$ death of immature snails after three hours of sunlight exposure using concentrations up to $15 \mu \mathrm{g} / \mathrm{ml}$. While, the lethal effect on egg masses observed in the present study was also noticed by (Mahmoud et al., 2013) who reported 70\% death of egg masses after three hours using concentrations up to $15 \mu \mathrm{g} / \mathrm{ml}$ compared to $100 \%$ death of snails exposed to the same experimental conditions, denoting a lower effect on egg masses.

On the other hand, the effect of chlorophyllin on infected snails resulted in a greatly enhanced lethal effect compared to uninfected adult snails $(6-8 \mathrm{~mm})$. This may be explained by the added effect of photosensitization induced cellular damage to the already weakened snails.

Histopathological examination for assessment of the photosensitization effect of chlorophyllin on snail's tissues observed its destructive effect on different cells. However, studies assessing phototoxicity at sub-cellular level are difficult because of the extreme complexity of cells (Spikes, 1989).

While, during present study for the effect of chlorophyllin on miracidia and cercariae, it was found that it had a larvicidal effect which was mainly dependant on both incubation and exposure time to sunlight. This larvicidal effect of chlorophyllin was different from other photosensitizers like carbamide perhydrate which had no biocidal activity against $S$. mansoni miracidia and cercariae even after their exposure to double the $\mathrm{LC}_{50}$ or $\mathrm{LC}_{90}$ for 20 minutes in sunlight (Gawish et al., 2009)

From the foregoing results, It is concluded y that chlorophyllin is a promising plant derived product with potential molluscicidal and larvicidal proprieties. Further evaluation and conditions for optimization their effects were urgently required for efficient field application is recommended.

\section{References}

Barakat, R. M. R.2013. Epidemiology of Schistosomiasis in Egypt: Travel through Time: Review. J Adv Res, 4(5), 425-432.

Bhattacharyya, T., Ayandeh, A., Falconar, A. K., Sundar, S., El-Safi, S., Gripenberg, M. A., Miles, M. A. 2014. IgG1 as a potential biomarker of postchemotherapeutic relapse in visceral leishmaniasis, and adaptation to a rapid 
diagnostic test. PLoS Negl Trop Dis, 8(10), e3273. doi: 10.1371/journal. pntd. 0003273

Costa, L. E., Goulart, L. R., Pereira, N. C., Lima, M. I., Duarte, M. C., Martins, V. T.,... Coelho, E. A. 2014. Mimotopebased vaccines of Leishmania infantum antigens and their protective efficacy against visceral leishmaniasis. PLoS One, 9(10), e110014. doi: 10.1371/ journal.pone.0110014

El-Tarky, A. E. 2005. Semi field studies to control schistosomiasis free larval vectors using selected sensitizers with sun light and laser radiation. Ph.D. thesis, National Institute of Laser Enhanced Science, Cairo University, Egypt.

El-Tayeb, T. 2003. Laser scanning microscopy for determination of the efficiency of hematoporphyrin in control of Culex pipiens larvae and the snail vector of Fasciola gigantica. Ph.D. Thesis. National Institute of Laser Enhanced Sciences, Cairo University, Egypt.

Erzinger, G. S., Wohllebe, S., Vollrath, F., Souza, S. C., Richter, P., Lebert, M., and Häder, D.-P. 2011. Optimizing conditions for the use of chlorophyll derivatives for photodynamic control of parasites in aquatic ecosystems. Parasitology research, 109(3), 781-786.

Finney, D. J. 1970. Probit Analysis, 3rd ed. London Cambridge University Press.

Gawish, F. A., El-Sherbini, S., and Aly, H. F.2009. Effect of photosensitization process of carbamide perhydrate on Biomphalaria alexandrina snails and their infection with Schistosoma mansoni. J Appl Sci Res, 5, 46-56.

Graham, K. 1963. Concepts of forest Entomology. New York, NY: Reinhold Publ Corp/Chapman and Hall Ltd.

Jaiswal, P., and Singh, D.2008. Molluscicidal activity of Carica papaya and Areca catechu against the freshwater snail Lymnaea acuminata. Veterinary parasitology, 152(3), 264-270.

Jaiswal, P., Singh, V., and Singh, D.2008. Enzyme inhibition by molluscicidal component of Areca catechu and Carica papaya in the nervous tissue of vector snail Lymnaea acuminata. Pesticide biochemistry and physiology, 92(3), 164-168.

King, C. H. (2009). Toward the elimination of schistosomiasis. N Engl J Med, 360(2), 106-109.

Kumar, P., and Singh, D.2006. Molluscicidal activity of Ferula asafoetida, Syzygium aromaticum and Carum carvi and their active components against the snail Lymnaea acuminata. Chemosphere, 63(9), 1568-1574.

Lotfy, W. M. 2009. Human schistosomiasis in Egypt: historical review, assessment of the current picture and prediction of the future trends. J Med Res Inst, 30, 1-7.

Luksiene, Z. 2005. New approach to inactivation of harmful and pathogenic microorganisms by photosensitization. Food Technol Biotechnol, 43(4), 411418.

Mahmoud, M. S., Richter, P., Shalaby, H. A., Kandil, O. M., and Hader, D. P. 2013. Molluscicidal activity of chlorophyll extraction against the freshwater snails. J Coast Life Med, 1(2), 85-88. doi: 10.12980/jclm.1.2013c824

McCullough, F. S.1992. The role of mollusciciding in schistosomiasis control. Geneva, Switzerland: WHO.

Mostafa, S. S., and Gawish, F. A. 2009. Towards to control Biomphalaria alexandrina snails and the free living larval stages of Schistosoma mansoni using the microalga Spirulina platensis. Austr. J. Bas. Appl. Sci, 3(4), 41124119.

Ragheb, M. 2013. Photothermal and photosensitization, novel control 
modalities on certain biological and histological parameters of Biomphalaria alexandrina snails. Ph.D. Thesis. Faculty of Science, Cairo University, Egypt

Ragheb, M., El-Tayeb, T., Al Emam, M., Amer, M., and Bashtar, A. 2013. Copper chlorophyllin and magnesium chlorophyllin as molluscicidal agents against Biomphalaria alexandrina snails Asia Acad Res J Multidiscip, 1(16), 229-254.

Redmond, R. W. 2008. Photophysics and Photochemistry in Photodynamic Therapy. In M. R. H. and and P. Mroz (Eds.), Advances in Photodynamic Therapy: Basic, Translational, and Clinical (pp. 41-58). Boston and London: Artech House.

Salama, E. M., El-Sherbini, S., Abdel-Kader, M. H., and Jori, G. 2002. Site of action of hematoporphyrin (a photo-activated insecticide) in Culex pipiens larvae. Egypt J Biol, 4, 133-141.

Srivastava, P., and Singh, D. 2005. Control of harmful snails: Tejpat (Cinnamomum tamala) a potential molluscicide. $J$ Appl Biosci, 31(2), 128-132.

Spikes, J. 1989. Photosensitization. In S. C. K (Ed.), The Science of photobiology (second edition ed., pp. 79-110). New york USA: plenum press.

SPSS, (2006). Statistical Package for Social Science, SPSS for windows Release 16.0.0, and 12 June, 2006. Standard Version, Copyright SPSS Inc., 19892006, All Rights Reserved, Copyright ${ }^{\circledR}$ SPSS Inc.

Useh, M. F. 2012. Control of schistosomiasis. In M. B. Rokni (Ed.), Schistosomiasis (pp. 73-102): InTech.

Wohllebe, S. 2010.Combating parasites in aquatic ecosystems by natural photosensitizers. Ph.D. Thesis. University of Erlangen, Erlangen, Germany.

Wohllebe, S., Richter, P., and Häder, D.-P. 2012. Chlorophyllin for the control of Ichthyophthirius multifiliis (Fouquet). Parasitology research, 111(2), 729-733.

Wohllebe, S., Richter, R., Richter, P., and Häder, D.-P. 2009. Photodynamic control of human pathogenic parasites in aquatic ecosystems using chlorophyllin and pheophorbid as photodynamic substances. Parasitology research, 104(3), 593-600.

\section{How to cite this article:}

Heba A. Elhadad, Bassem A. El-Habet, Rania M. Azab, Hanaa M. Abu El Einin, Wael M. Lotfy and Hassan A. Atef. 2018. Effect of Chlorophyllin on Biomphalaria alexandrina Snails and Schistosoma mansoni Larvae. Int.J.Curr.Microbiol.App.Sci. 7(03): 3725-3736. doi: https://doi.org/10.20546/ijcmas.2018.703.431 